This item was submitted to Loughborough's Research Repository by the author.

Items in Figshare are protected by copyright, with all rights reserved, unless otherwise indicated.

\title{
Delivering criticism through anecdotes in interaction
}

PLEASE CITE THE PUBLISHED VERSION

http://dx.doi.org/10.1177/1461445616668069

PUBLISHER

(c) The Author. Published by Sage

VERSION

AM (Accepted Manuscript)

PUBLISHER STATEMENT

This work is made available according to the conditions of the Creative Commons Attribution-NonCommercialNoDerivatives 4.0 International (CC BY-NC-ND 4.0) licence. Full details of this licence are available at: https://creativecommons.org/licenses/by-nc-nd/4.0/

\section{LICENCE}

CC BY-NC-ND 4.0

\section{REPOSITORY RECORD}

Pino, Marco. 2016. "Delivering Criticism Through Anecdotes in Interaction”. Loughborough University. https://hdl.handle.net/2134/21231. 


\title{
Delivering criticism through anecdotes in interaction
}

\author{
Marco Pino ${ }^{1}$
}

Published as Pino, M. (2016). Delivering criticism through anecdotes in interaction.

Discourse Studies 18(6), pp. 695-715.

\begin{abstract}
Criticising someone's conduct is a disaffiliative action that can attract recipient objections, particularly in the form of defensive detailing by which the recipient volunteers extenuating circumstances that undermine the criticism. In Therapeutic Community (TC) meetings for clients with drug addiction, support staff regularly criticise clients' behaviours that violate therapeutic principles or norms of conduct. This study examines cases where, rather than criticising a client's behaviour directly, TC staff members do so indirectly through an anecdote: a case illustrating the inappropriateness of the type of conduct of which the client's behaviour is an instantiation. TC staff members design the anecdote to convey a principle or norm of conduct which the client has putatively violated, and they systematically pursue endorsement of that principle by the client. By constructing the anecdote as an exemplary case, distanced from the individual client's personal experience, TC staff members make it an empirically unverifiable, self-evident, and therefore hard to challenge, illustration of a norm.
\end{abstract}

\section{Keywords}

Addiction, anecdote, conversation analysis, criticising, disaffiliation, exaggeration, Therapeutic Community

\footnotetext{
${ }^{1}$ Department of Social Sciences Loughborough University Brockington Building, Margaret Keay Rd, Loughborough, Leicestershire LE11 3TU, UK Email: M.Pino@lboro.ac.uk
} 
Pino - Delivering criticism through anecdotes in interaction

\section{Introduction}

Research on language and social interaction has documented a preference for actions that promote social solidarity (Lindström and Sorjonen, 2013). Consistently through ordinary and institutional settings, people design their social actions in ways that promote affiliation, agreement and so on (Pomerantz and Heritage, 2013). However, everyday life is also punctuated by social occasions that require taking a negative position towards others, such as when bringing to others' attention that they have acted inappropriately. A practical problem that members face in these cases is how to convey disaffiliation without disrupting or comprising their relationship with others. This problem is especially salient in professional-client interactions with a focus on correcting or modifying client behaviours for therapeutic or educational purposes (MacMartin and LeBaron, 2006). This study focuses on the case of Therapeutic Community (TC) group meetings for clients with drug or alcohol addiction. The TC rehabilitation approach has a focus on learning through living together within the residential space of the community, and a significant part of the therapeutic process involves fostering some kind of change (e.g. discontinuation, modification or substitution) in clients' behaviours that are regarded as maladaptive, dysfunctional or simply inappropriate for the residential setting. TC staff members commonly initiate this process by conveying to their clients that some aspect of their conduct is or has been problematic - in this study I refer to this type of action as criticising a client behaviour.

Criticising someone's conduct is a disaffiliative social action which can carry negative implications for some aspect of the recipient (their moral outlook, competence etc.). When TC staff members set out to criticise a client's conduct, they regularly face two practical problems: How to secure agreement/acceptance? and How to pre-empt or manage emerging client disaffiliation? This study examines a practice that TC staff members use to minimise client rejection of criticism: the interactional use of anecdotes. An anecdote is the conversational representation of a real or a fictional event used to convey a principle of conduct, which a client has putatively violated. Through the use of anecdotes, TC staff members speak indirectly about a client's misdemeanours or shortcomings through stories that allude to but are not directly 'about' the client's particular misdeeds. The anecdotes, of real or imagined events, are displaced from and do not purport to be 'about' the client's actual behaviour. The use of anecdotes enables TC staff members to highlight a client's shortcomings/misdeeds without directly referring to the client's behaviour, and therefore without directly criticising the client. In this study I demonstrate that TC staff members use this practice to interdict client access to a resource that they can otherwise use to deflect or fend off criticism: defensive circumstantial detailing (Jefferson, 1985). In TC meetings, clients regularly use this form of defence when TC staff members criticise them directly. Before moving on to the use of anecdotes, Extract 1 illustrates what commonly happens when TC staff members directly criticise a client's conduct.

(1) IntL2:287 55:27 'Housework' 
Pino - Delivering criticism through anecdotes in interaction

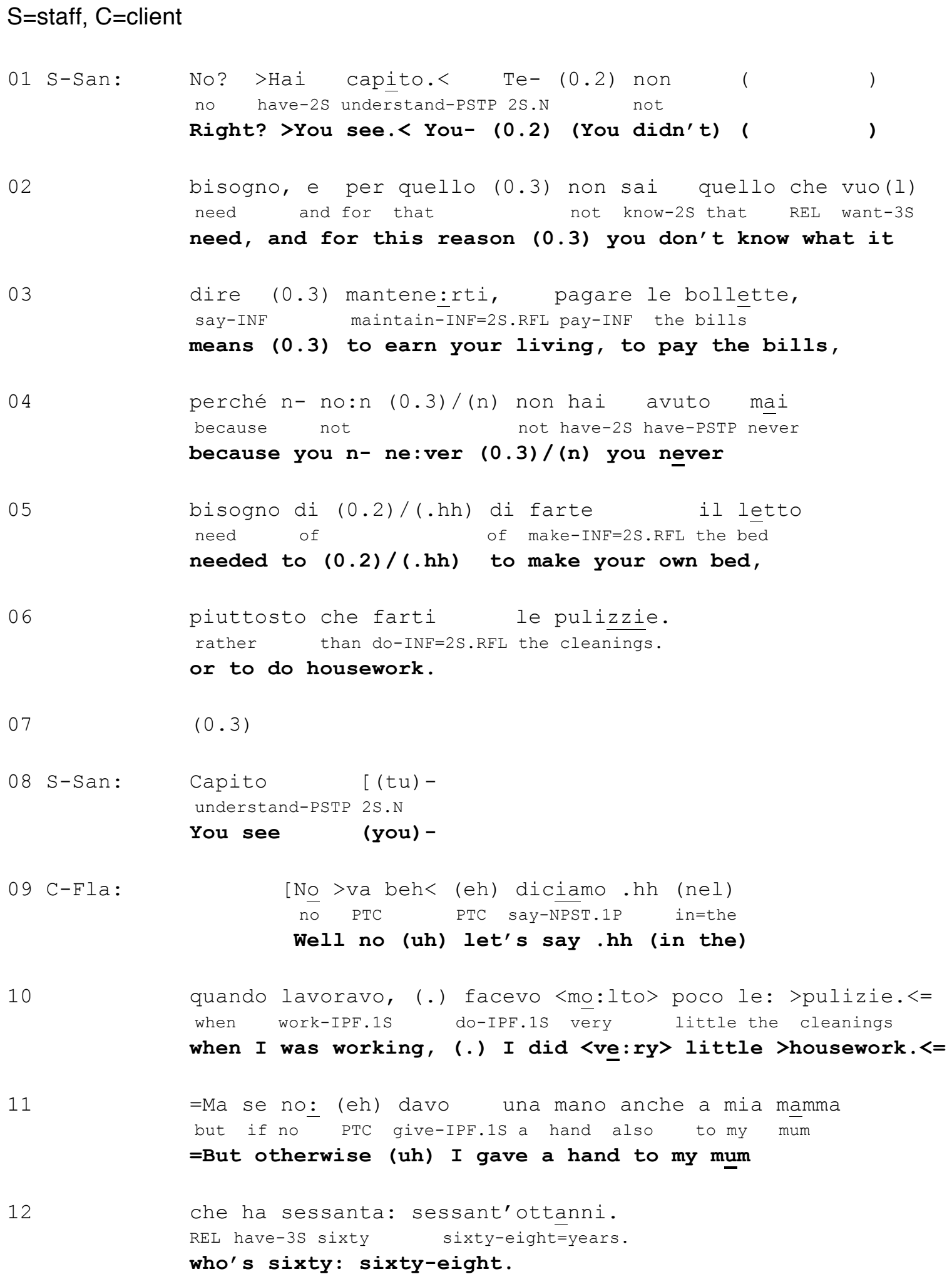

In Extract 1 Sandro (staff) describes Flavio's (client) conduct in negatively valued terms (e.g. he did not perform tasks that an adult can be expected to perform, such as earning his own living, etc.; lines 1-6). This type of criticism systematically provides clients with an opportunity to engage in circumstantial defensive detailing; by way of volunteering details on the criticised behaviour, clients can convey that their conduct has not been properly 
understood and that it is not as bad as the staff have portrayed it. Here Flavio reports that, at least sometimes, he helped his mother in the housework (lines 9-12). This factual correction of Sandro's description undermines the relevance or applicability of his conveyed criticism.

Anecdotes are a more circuitous way of pointing out the inappropriateness of a client's behaviour without describing or evaluating it. Also, anecdotes are designedly harder to challenge because clients cannot claim privileged access to the circumstances portrayed in them as they can do when their own real-life conduct is under discussion (Heritage, 2011). Because they are designed to resist empirical testing and challenge, anecdotes bear similarities with idioms and hypothetical cases. Idioms can be used used to promote recipient affiliation to complaints:

'idiomatic expressions remove the complaint from its supporting circumstantial details. This may give such expressions a special robustness: since they are not to be taken literally, they may have a certain resistance to being tested or challenged on the empirical facts of the matter.' (Drew and Holt, 1988p. 406)

Similarly, anecdotal cases are designed to resist empirical challenge because they do not contain empirical details that can be contested or verified. However, idioms are different from anecdotes in that they follow - and usually condense the upshot of - a description of the complained-of conduct. Anecdotes are used as alternatives to the description of a recipient's conduct; as I will show, they allow TC staff members to bypass that description when conveying criticism.

Hypothetical scenarios can be used to promote recipient cooperation in circumstances where this may not be forthcoming. HIV/AIDS counsellors introduce hypothetical cases to pursue client talk about dying in circumstances where clients have passed on previous opportunities to engage in that type of talk (Peräkylä, 1995, pp. 280286). By asking how clients would feel or act in a hypothetical scenario were they became ill, HIV/AIDS counsellors interdict client access to a resource that clients can use to avoid answering questions about their situation, i.e. claiming that their current situation is no cause for concern (Peräkylä, 1995, P. 309). Like idioms and anecdotes, hypothetical cases are designed to resist empirical challenge because their details are incontestable and unverifiable (they are mere possibilities). Hypothetical cases are also different from anecdotes: in HIV/AIDS counselling, hypothetical cases are treated as scenarios that can materialise in the future, and clients are encouraged to think about those possible scenarios (Peräkylä, 1995, pp. 299-300). By contrast, TC staff members treat the specific circumstances represented in their anecdotes as secondary and instrumental to conveying a norm of conduct. This is evidenced in TC staff members' treatment of different types of anecdote (different in content and shape) as interchangeable; as I will show in 'Anecdotes Are Used to Interdict Client Access to Defensive Detailing' section, many anecdotes can be used to convey the same principle. 
The aim of this study is to examine the interactional use of anecdotes in implementing criticism, and to demonstrate that anecdotes are used and oriented to as an alternative to the practice of direct criticism, specifically because they maximise recipient acceptance by interdicting recipient access to the resource of defensive circumstantial detailing. Although in this study I focus on the case of TC meetings, the findings are relevant for a wide range of professional-client interactions in therapeutic and educational settings where professionals are tasked with fostering some kind of change in their clients' conduct (Arminen and Halonen, 2007; MacMartin and LeBaron, 2006; van Nijnatten and van Elk, 2015).

\section{Methods}

Data for this study were collected in three TCs in Italy (a residential TC for people with drug addiction, a residential TC for people with drug addiction and mental health issues, and a semi-residential TC for young adults with drug addiction) between 2009 and 2014. These TCs delivered intensive (residential or semi-residential) rehabilitation programs involving daily work, educational, and leisure activities. Meetings between all the clients and a number of staff members (who usually took turns in chairing the meetings) happened in each TC on a weekly basis. The staff members had a background in education, social work or psychology. The clients had diagnoses of drug and/or alcohol addiction, and sometimes mental health issues (so called co-morbidity). In the data for this study the number of staff per meeting varied from 1 to 4 , and the number of clients from 3 to 16 . Data consist of 24 audio or video-recorded meetings lasting 26 hours in total (the instances used in this paper are taken from video-recorded meetings).

I used Conversation Analysis to collect, transcribe and analyse staff members' use of anecdotes to criticise clients' conduct. My approach was to identify extended episodes where the group focused on some client problematic behaviour, which was treated as violating a norm of conduct or a therapeutic principle. The target behaviours had either occurred in the meeting, in a recent past (usually the week before the meeting), or in a more distant past (clients' life before admission to the TC). I identified 25 episodes in which TC staff members used anecdotes (usually more than one) to deliver client criticism. The instances in this paper are illustrative of patterns identified across these cases. The data are displayed in three-line transcripts containing the original language (Italian, with occasional use of a local dialect), an interlinear gloss and an idiomatic English translation. Transcription conventions and abbreviations are provided in the Appendix. Participants gave written informed consent for the transcripts to be published; all names in this paper are pseudonyms.

\section{Results}


When a client's inappropriate behaviour is brought to the attention of the group, rather than directly criticising that behaviour, TC staff members can describe an anecdotal case illustrating a norm or principle that the client has putatively violated. This enables TC staff to convey criticism without directly commenting on the client's target behaviour. The circumstances in which the target behaviour originally emerged are transposed into an illustrative case scenario which displays visible connections with the circumstances of the real case ('Anecdotes Are Transpositions of Client Circumstances' section). The staff use anecdotes to deliver a point or upshot, which coincides with a norm or principle of conduct that the client allegedly violated ('Anecdotes Convey a Point or Upshot That Applies to the Clients' Cases' section). Anecdotes are designed to resist empirical testing by way of being built as exemplary cases, distanced from the real-life circumstances in which the client's problematic conduct emerged ('Anecdotes Are Used to Interdict Client Access to Defensive Detailing' section).

\section{Anecdotes are transpositions of client circumstances}

Rather than directly criticising a client's behaviour, TC staff members transpose or represent the circumstances in which that behaviour emerged within the narrative framework of an anecdote. The anecdote is designed to deliver a point that will apply, mutatis mutandis, to the client's behaviour (see 'Anecdotes Convey a Point or Upshot That Applies to the Clients' Cases' section). However, TC staff usually do not flag the relationship between the real-case circumstances and those represented in the anecdote in any overt manner. The connection between the anecdotal case and the client's real case is made available through the details of the anecdotal case and left to be inferred. This can be seen in Extract 2.

(2) IntG1:91 19:42 'Video games'

$\mathrm{S}=$ staff, $\mathrm{C}=$ client

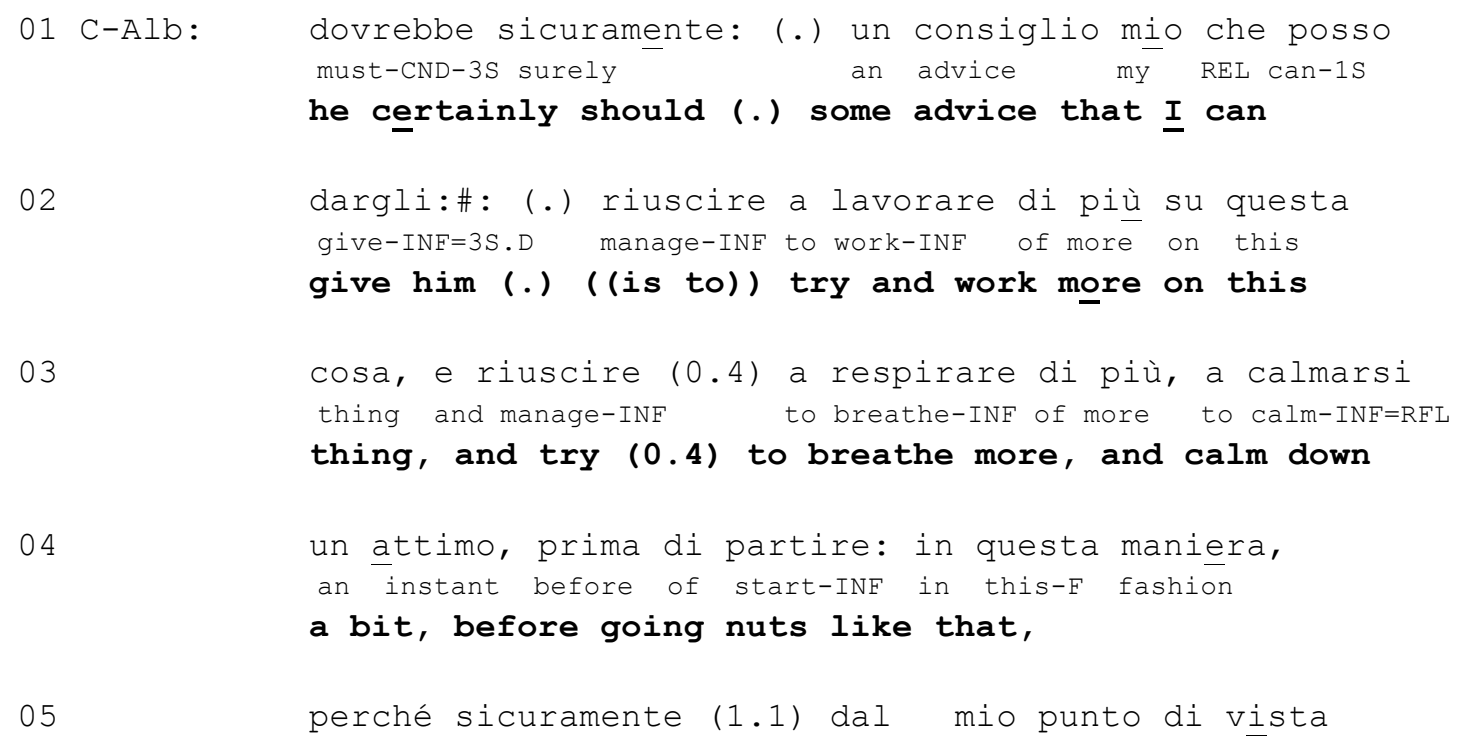


Pino - Delivering criticism through anecdotes in interaction

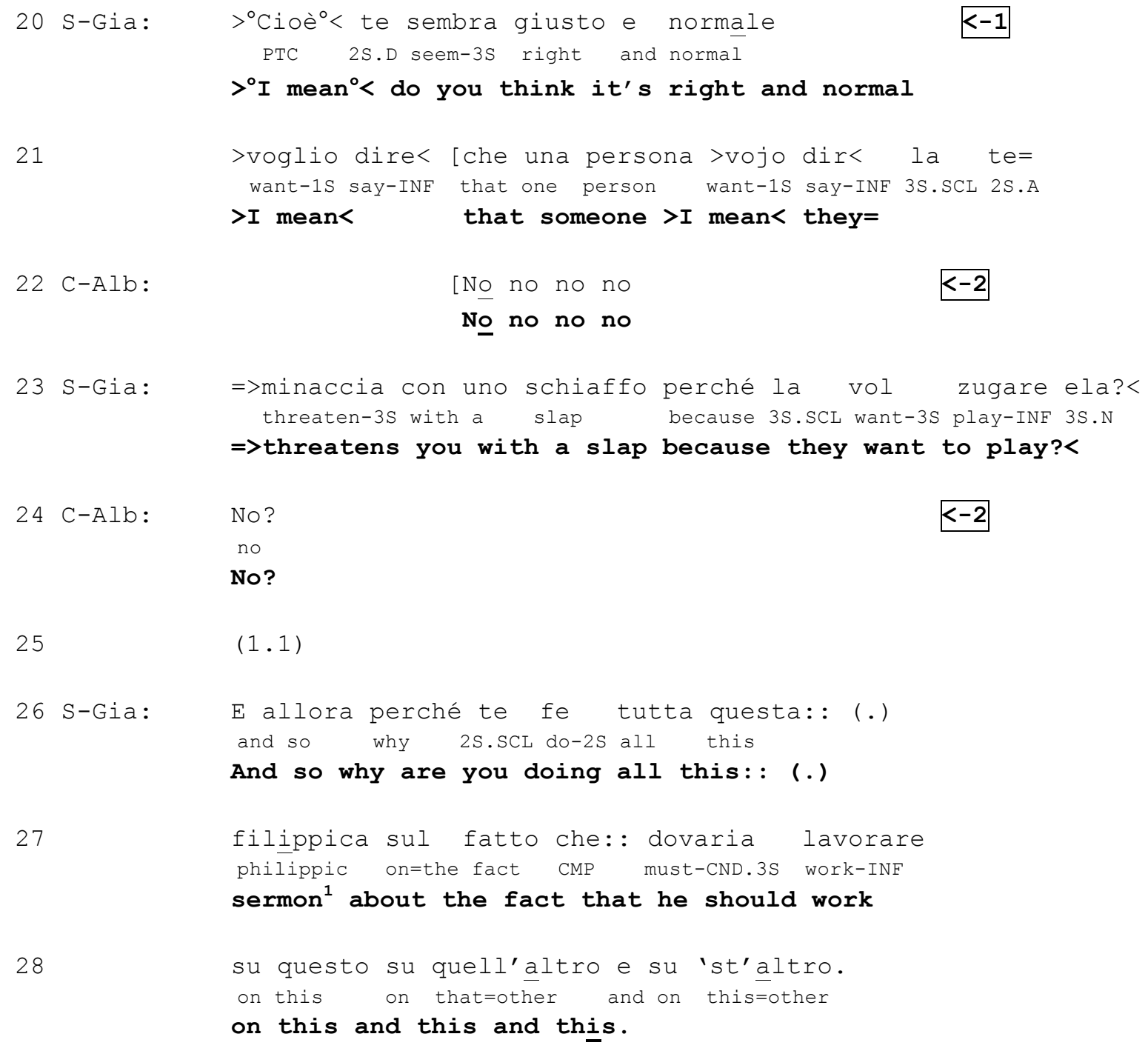

Before Extract 2, Alberto (a client) reported being threatened by another client (Dario) some days before the meeting, in the context of a dispute about whose turn it was to play with a video game console. Alberto reported that Dario threatened him with physical violence ("And at that point I took the CD that he had put in, I pulled it out, and he came to me (.) and he told me 'Look I'll give you a slap.'", data not shown). After this reporting, at lines 1-6, Alberto gives Dario some advice. From line 9, Gianni (staff) delivers an anecdote to illustrate that Alberto's rather restrained position towards Dario (particularly its 'psychologising' character) is an insufficient and inadequate reaction to the magnitude of the episode. Gianni designs the anecdote as an illustrative case of the type of circumstance that Alberto reported. The case presents recognisable connections to the original story. It involves Alberto as a character in a hypothetical future situation which happens in a bar rather than the TC (line 9); it involves a dispute over access to playing a game (pinball rather than a video game console; lines 9-10), and an act of violence against Alberto (although it is an actual slap rather than the threat of it, lines 10 and 12). Furthermore, Gianni displays an orientation to this connection by suggesting that the anecdotal case bears implications for the assessment of Alberto's conduct in the real case; by challenging Alberto to say whether 
he would deal with the offender in the anecdotal case through a "psychological analysis" of him (Koshik, 2003), Gianni indirectly caricaturizes Alberto's reaction to the threat that he received in the real case (lines 1-4). Additionally, in his response Alberto refers to the anecdotal case as "that case" ("Io non avrei fatto niente in quel caso" / II wouldn't have done anything in that case"; lines 18-19), thus possibly displaying an orientation to the anecdote as a case that is not designed to be understood in isolation but in its relationship with the real case. Extract 3 provides another instance.

(3) - IntL2:381 58:20 'Bleach’

$\mathrm{S}=$ staff, $\mathrm{C}=$ client

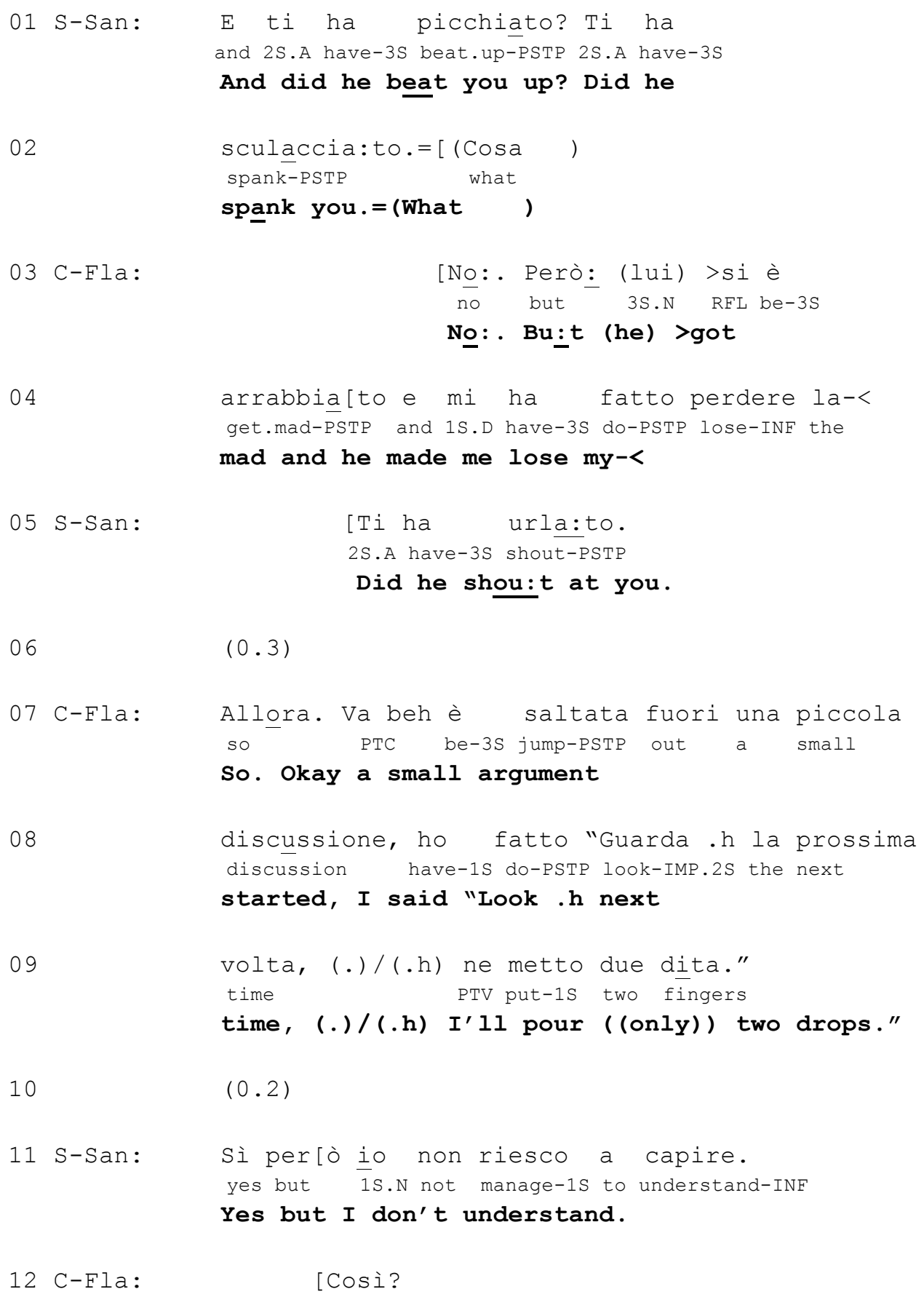


Pino - Delivering criticism through anecdotes in interaction

like.this

That's it?

$(0.9)$

14 S-San:

Adamo.

(0.2) (Vai

eh-

) Riprendiamo questo.

(.)

NAME

go-IMP.2S PTC

Adamo.

(0.2) (Go uh-) Let's revisit this.

15

Io sono: (0.3) e:: : : F Flavio. Te sei Ilario.

1S.N be-1S PTC NAME 2-S.N be-2S NAME

I am (0.3) u::::h Flavio. You are Ilario.

16

Te mi dici (.) Vai Adamo. Dimmi.

$2 \bar{S} \cdot N$ 1S.D say-2S (.) go-IMP.2S NAME say-IMP.2S=1S.D

You tell me (.) Go Adamo. Téll me.

$(0.3)$

18 C-Ada :

Eh quanta candeggina hai me:sso.

PTC how.much bleach have-2S put-PSTP

Right how much bleach did you use.

$(0.3)$

20 San:

E:h no: e: : : h ho messo un: : un po' di-

PTC no PTC have-1S put-PSTP a a bit of

U:h no: u: $:$ h I used a: : a bit of-

21

m: messo un goccio.

put-PSTP a drop

I u: used ((just)) a bit.

22 C-Ada: (Tieni la mano), perché se no restiam keep-IMP.2s the hand because if not remain-1P

(Use less bleach), because otherwise

se:nza.

without

we finish it.

$(0.4)$

25 S-San:

$\underline{A}[: h$ (no) $]$ non lo sapevo: . Escusa.

PTC (not) not 3S.A know-IPF.1S sorry

$0: h$ I (di) I didn't know that. Sorry.

26 C-Ada :

[(Pero-) ]

( (unclear))

27 S-San:

[La prossima volta metto un po' di meno.= the next

time put-1s a bit of less

Next time I will use a bit less ((bleach)) .=

28 C-???: [Heh heh. 


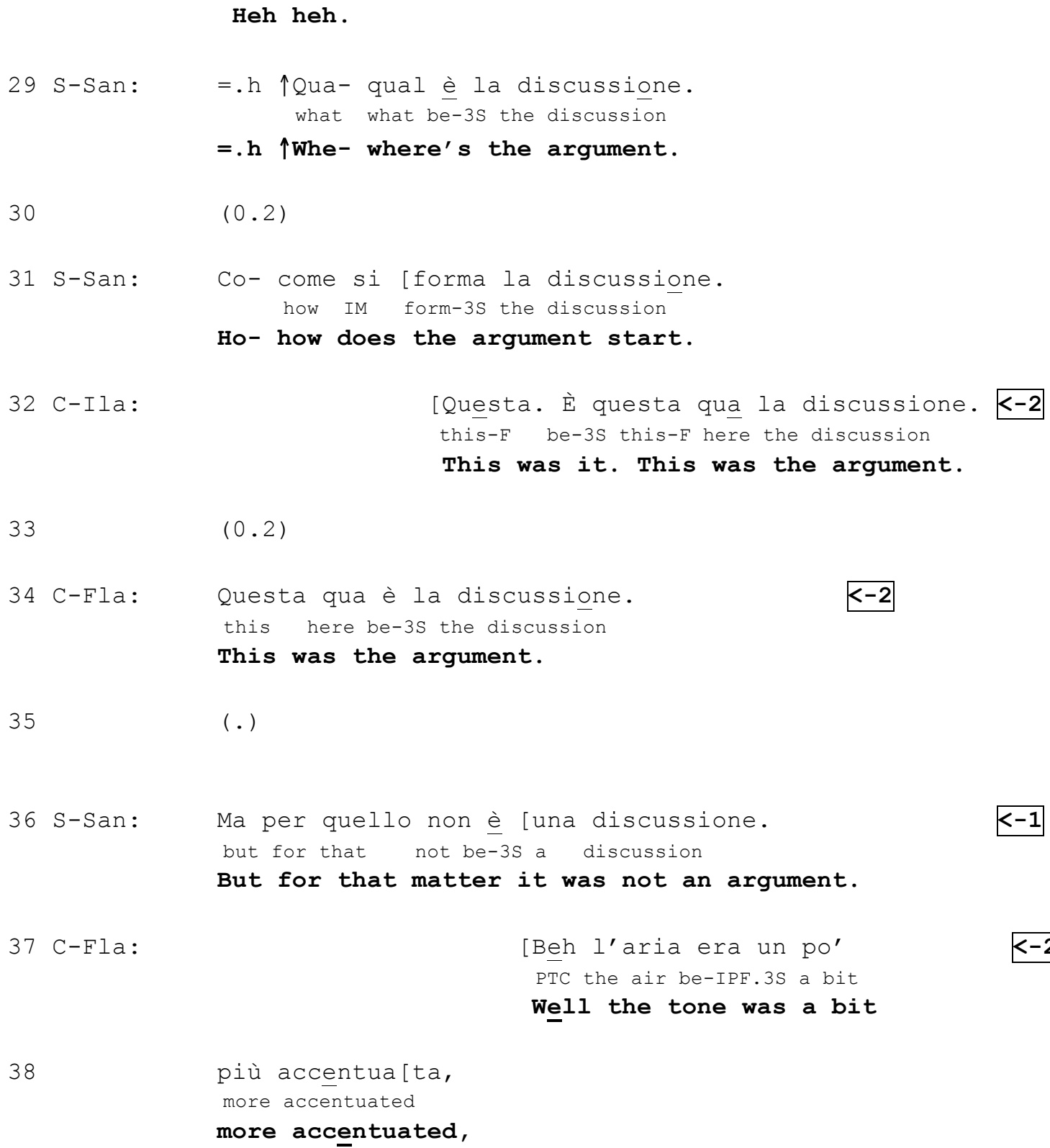

Before Extract 3, Flavio (a client) reported being told by another client called Ilario (on a day preceding the meeting) that he was using too much bleach whilst doing housework, and he referred to having a "reaction" (i.e. towards llario, alluding to an argument they had; data not shown). Sandro (staff) challenges Flavio, possibly both for his treatment of the episode as a complainable matter and for his reaction towards llario within that episode (lines 1-2 and 5). In line with a pattern observed throughout the TC data, the client responds to Sandro's conveyed criticism by engaging in circumstantial defensive detailing which can justify his reaction in the reported episode and his treatment of the episode as a complainable matter (lines 3-4; Drew, 1998); furthermore, it introduces extenuating circumstances to fend off Sandro's conveyed criticism (lines 8-9). At line 14, Sandro recruits another client (Adamo) to enact an anecdotal version of the episode recounted by Flavio (on enactment, Sandlund, 2014). The anecdotal case presents recognisable connections to the real case: it involves the same characters (Flavio and Ilario, enacted by Sandro and Adamo 
respectively), engaged in the same activity (Ilario criticising Flavio for using too much bleach), although the anecdotal episode has a different outcome (Flavio promptly accepts and apologises instead of getting into an argument with llario). At lines 32 and 34, the clients involved in the real case (Ilario and Flavio) display their understanding that the anecdotal case is not to be considered in isolation but in its implications for the assessment of the real case in which they were involved (e.g. "Questa qua è la discussione"/"This was the argument" treats the anecdotal case as a model against which to analyse the dynamic of the real case).

To summarise, anecdotal cases are designed and received as cases that should not be seen in isolation but in their relationship with, and in their implications for the assessment of the client's real case. The implication is that the principles conveyed through the anecdotal cases can be taken to apply to the client's case.

\section{Anecdotes convey a point or upshot that applies to the clients' cases}

Because the cases that TC staff members use are anecdotal, i.e. designed to deliver a point or upshot, and because they are recognisably connected to the clients' real cases (as shown in 'Anecdotes are transpositions of client circumstances' section), the conveyed points or upshots that apply to the anecdotal cases (and which the anecdotal cases illustrate) also apply to the clients' real cases, mutatis mutandis. The anecdotal nature of the cases is crucial for their action import, i.e. criticising clients' conduct. In fact, the points or upshots conveyed through the anecdotes are invariably principles or norms of conduct, which the clients have putatively violated. Using anecdotes enables TC staff members to allude to these violations rather than overtly claiming or describing them.

In Extract 2 (shown above) Gianni designs his anecdote to convey criticism of Alberto's rather composed and restrained treatment of another client's threat of physical violence. Gianni does so through an anecdote illustrating a principle of conduct (i.e. that one should react sharply towards or firmly reject any form of violence), which the client has putatively violated. The anecdote is designed to facilitate extraction and endorsement of this principle by way of being exaggerated (on exaggeration, Drew, 2003; on endorsement, Zemel, 2014). In the anecdotal version of the events Alberto receives a slap in the face, whereas in the real case he was only threatened with a slap (line 10). Exaggeration makes the case an unequivocal illustration of the putatively violated norm of conduct. This anecdote does not comprise an illustration of what would count as an appropriate or inappropriate response to violence; the narrative reaches a climax with the "big slap in the face" ("sciafon nel muso"; lines 10 and 12), and it does not illustrate how the protagonist reacts to it. Rather, Gianni solicits Alberto to articulate what he would do in the anecdotal/hypothetical scenario (lines 15-17); he thereby provides for the client himself to extract and appreciate the principle which he has putatively violated. There is evidence that Gianni's question/challenge at lines 15-17 provides for Alberto to extract and endorse the upshot of the anecdote in terms of a putatively violated norm of conduct: when Alberto fails 
to extract and endorse the conveyed principle (lines 18-19) Gianni unpacks that principle and pursues its endorsement (lines 20-21 and 23). Furthermore, after the client eventually endorses the principle (lines 22 and 24), Gianni uses this endorsement as a basis (" $E$ allora" /"And so") for now overtly challenging Alberto's measured response to the threat that he suffered in the real case (lines 26-28). This strongly suggests that Gianni introduced the anecdote as part of an interactional project to convey criticism of Alberto's conduct in the real case. By endorsing the principle conveyed through the anecdote (which constitutes a narrative illustration of the class of possible events to which Alberto's real case putatively belongs; lines 22 and 24), the client puts himself in a position where his conduct in the real case can now be seen as inadequate, if it was applied in the anecdotal case; and because the anecdotal case belongs to the same class of possible events as the client's real case, that conduct can be seen as inadequate in the real case as well. Gianni observably orients to this conclusion as an inference that can and should be made (" $E$ allora perché te fe tutta questa filippica"/"And so why are you doing all this sermon", etc., lines 26-28). The use of an anecdote has therefore enabled Gianni to make criticism emerge without directly commenting on Alberto's conduct (Drew, 1992).

In Extract 3 (shown above), the anecdote illustrates the principle that it is not acceptable to get into a quarrel for trivial reasons, such as being criticised for using too much bleach. Unlike Extract 2, this anecdote illustrates what would count as appropriate conduct in that circumstance (i.e. prompt acceptance of criticism/advice, line 25). Exaggeration designedly facilitates extraction and endorsement of the conveyed principle; in fact, the 'Flavio' character in the anecdotal case is portrayed as having such an accepting and apologetic demeanour (lines 25,27) that it occasions laughter from an unidentified client (lines 28; Sandlund, 2014). Additional evidence that the anecdote is designed to deliver a principle is to be found in lines 29 and 31 where Sandro solicits its extraction and endorsement; here Sandro challenges the clients to provide grounds for having an argument in the circumstances portrayed in the anecdote, whilst implying that such grounds do not exist. As in Extract 2, when extraction and endorsement of the conveyed principle is not forthcoming (at lines 32 and 34 the clients involved in the real case only confirm that they had the same type of argument that the anecdote illustrated) the staff member unpacks the import of the anecdotal case (line 36). By contesting that the anecdotal case can be considered an argument, Sandro provides for the appreciation of the contrast between the anecdotal case (illustrating how the client should have behaved, i.e. accept rather than contest) and the real case (where the client did contest, and where such contestation led to a dispute). Therefore, the anecdote exposes the client's violation of a norm of conduct without overtly claiming or stating that it does so. Evidence for this is that Flavio treats Sandro's turn at line 36 as pointing to a discrepancy between the anecdotal case and the real case; Flavio addresses this discrepancy by conceding that "the tone [of the argument in the real case] was a bit more accentuated" ("I'aria era un po' più accentuata"; lines 37-38). He therefore displays an understanding that Sandro's anecdote was designed to expose a client's shortcoming (i.e. having an argument for trivial reasons). The use of an anecdote has 
enabled the staff member to achieve this outcome without overtly commenting on or evaluating the client's behaviour.

The analyses reported so far suggest that the use of anecdotes relies on a syllogistic logic (Gill and Maynard, 1995) whereby, if the client's real case belongs to the same class of possible cases of which the anecdotal case is a typified instance, then the principle that applies to the anecdotal case (and which the anecdotal case is designed to illustrate) also applies to the real case. This is further supported by TC staff members' orientations to the anecdotal cases as typical, generalised and illustrative instances of classes of events to which the clients' real cases also belong. This orientation emerges in two ways in the data. First, when a client does not extract and endorse the principle conveyed through an anecdote, the TC staff unpack that principle and, at the same time, they reformulate the anecdotal case as a generalised case involving "people", "someone", and the like - rather than specific characters as in the original formulation of the anecdote. They thereby cue the client to how the anecdote should be understood, i.e. as a typified illustration of a norm, which is offered as a model against which to assess the client's conduct in the real case. In Extract 2, Gianni's pursuit of endorsement contains such a formulation ("te sembra giusto e normale [...] che una persona [...] la te minaccia con uno schiaffo"/ "do you think it's right and normal [...] that someone [...] threatens you with a slap"). Extract 4 is another example of this phenomenon.

(4) IntG5:113 21:57 'Old habits'

$\mathrm{S}=$ staff, $\mathrm{C}=$ client

01 C-Adr:

Perché: : : l'ho

passato anch'io l'alcol, e: so

because 3S.A=have-1S pass-PSTP also=1S.N the=alcohol and know-1S

Because I've also been into alcohol, and I know

02

cosa vuol di:re star da s[oli.

what want-3S say-INF stay-INF by alone-P

what it means to be alone.

03 S-Gia:

[L'alcol l'e- (.) l'esempio

the=alcohol (3S.SCL=be-3S) the=example

Alcohol wa- (.) Igor's

04

de Igor è un esempio voj' dire e::hm perché è un-

of NAME be-3S an example want-1S say-INF PTC because be-3S one

example is an example I mean $u:: h m$ because he is one-

05

perché è uno dei prossimi che andrà a casa

because be-3S one of=the next-P REL go-FUT.3S to home

because he is one of the next to go home

06

e tutto.

and everything

and all that.

07 C-Adr: Ah hah? 
PTC PTC

Uh huh?

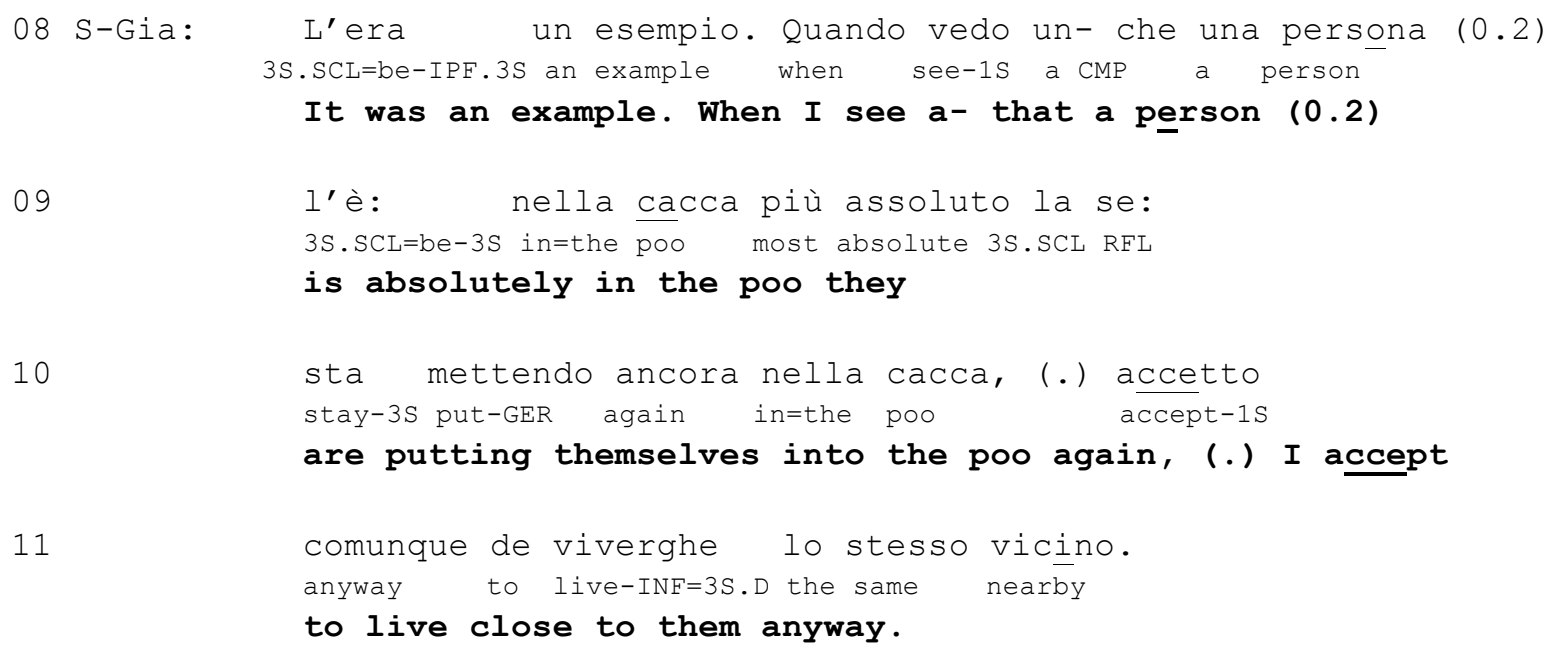

For space considerations it is not possible to give a full account of the target problematic conduct and the anecdote in the case of Extract 4. We come in at a point where Gianni has already introduced an anecdote in the form of a possible future scenario in which someone visits Igor (a client) after the end of the rehabilitation programme only to discover that Igor has started hanging out at the local bars and seeing the same people he used to see (which alludes to relapse into alcohol use). In the anecdotal case, the protagonist decides to hang out with Igor despite these visible signs that he may be relapsing (this illustrates the putatively violated norm of conduct). Following the pattern observed throughout the TC data, Gianni solicited extraction and endorsement of the principle (data not shown). At the start of Extract 4 a client is extracting and appreciating the upshot of the anecdotal case (lines 1-2). However, Gianni treats this as the wrong upshot on the basis that it is focused on the alcohol problem of the client depicted in the anecdote (Igor; lines 3-6); Gianni then unpacks a much broader principle which he provides for the client to endorse at lines 8-11 (that one should not interact with people who are "nella cacca"/"in the poo", a literal translation of an idiomatic expression which, in this case, alludes to relapse; Drew and Holt, 1988). In the process of soliciting that endorsement, Gianni issues another description of the type of event that illustrates the principle, now attributed to a generalised agent ("una persona" /"a person", line 8) rather than a specific character. He thereby cues the client to how the anecdote should be understood, i.e. as an exemplary case, offered to illustrate the validity of a norm of conduct and designed to apply to a broad spectrum of possible situations. In Extract 4, Gianni conveys that the applicability of the anecdote extends beyond the case of Igor and his problems with alcohol, to a much broader class of possible problems in which any of the clients could get involved.

A second way in which TC staff members display an orientation to the anecdotes as generalised, typical illustrations of a principle of conduct (and its violation), is that they exhibit disinterest in the details of the anecdotal episode as such, which they treat as secondary and instrumental to the delivery of a point or upshot. This emerges in TC staff 
members' treatment of the anecdotal cases as interchangeable; when clients do not extract or endorse the conveyed principle, TC staff members recurrently deliver another anecdote (which is often a different type of anecdote). This is examined at the start of 'Anecdotes Are Used to Interdict Client Access to Defensive Detailing' section (see the analysis of Extract 5).

\section{Anecdotes are used to interdict client access to defensive detailing}

TC staff members treat the details of the anecdotes as interchangeable and instrumental illustrations of a principle. This can be seen in cases in which clients do not extract and endorse the principle that the anecdote is designed to convey, and TC staff members pursue endorsement by introducing another anecdote illustrating the same principle. Later in the same meeting from which Extract 4 (shown above) is taken, Adriano (a client) further fails to extract and endorse the principle that one should avoid hanging out with people who are or may be relapsing (data not shown). Subsequently Gianni pursues endorsement by introducing a different anecdote; this is shown in Extract 5.

(5) IntG5:149 23:02 'Old habits 2'

S=staff, $\mathrm{C}=$ client

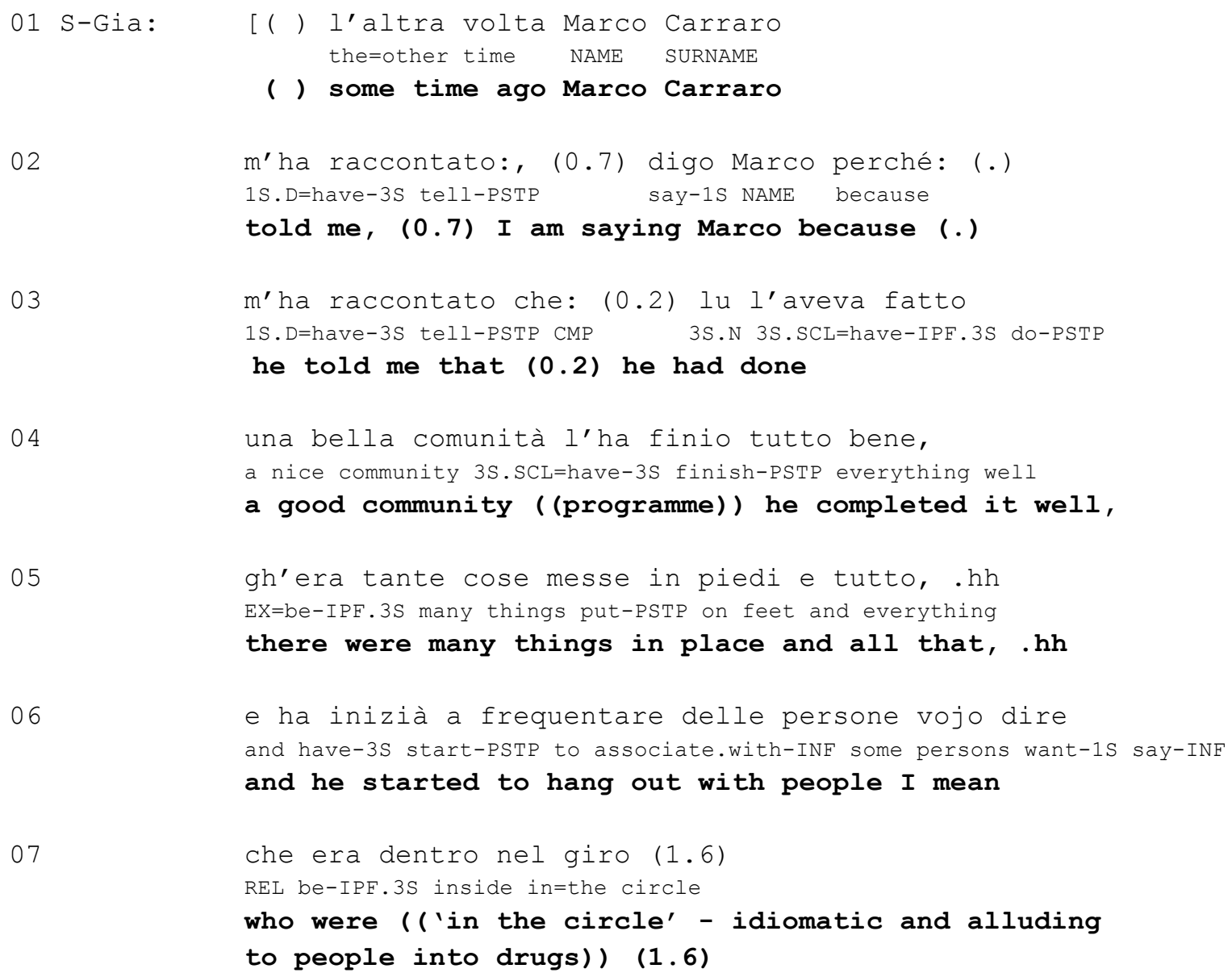


Whereas Gianni has previously used a hypothetical future scenario to illustrate the principle (summarised in 'Anecdotes Convey a Point or Upshot That Applies to the Clients' Cases' section), in Extract 5 he recounts the story of a real, co-present client (Marco) to illustrate the same principle, and the negative consequences of its violation: Marco started hanging out with people who used drugs; later in the meeting, in data not shown, it emerges that, as a result of this, he relapsed. This phenomenon further supports the point made in in 'Anecdotes Convey a Point or Upshot That Applies to the Clients' Cases' section: by switching to a different type of anecdote, TC staff members cue their clients to consider each anecdote as an instrumental illustration of a norm of conduct (and its violation), and to consider the specifics of the anecdote (i.e. who the protagonist is, whether it is an imaginary or a real event, etc.) as secondary to conveying a principle and its relevance for the clients.

The staff members' treatment of anecdotes as interchangeable also points to another key feature: the anecdotes are designed to resist empirical testing. When TC staff directly criticise some client behaviour, clients regularly engage in defensive circumstantial detailing by drawing on their privileged access to the circumstances of the criticised conduct (see Extracts 1 and 3). TC staff members try to interdict clients' access to this defensive resource by introducing illustrative cases over which they can exert some narrative control, such as the fictional rendition of a past event in Extract 3, the hypothetical future scenario in Extract 2, and the historical case of a different client than the client whose conduct is under scrutiny in Extract 5. Because clients cannot claim privileged access to the details of those cases as they can do with their own life experiences (Heritage, 2011), they also lack privileged resources for contesting the assessment of those cases. TC staff members seem to treat different types of anecdote as interchangeable because the circumstances portrayed in them are always distanced from the individual client's personal experience and because they are equivalent in their function: they all serve the purpose of illustrating a putatively violated norm of conduct.

There are two types of evidence that TC staff members actively use anecdotes to interdict clients' access to epistemic resources that they can use for defensive detailing. First, they use anecdotes to address and manage clients' use of defensive detailing. In Extract 3 (shown above), when Flavio responds to Sandro's conveyed criticism with defensive detailing (lines 3-9), Sandro introduces an anecdote (line 14). There is a clear advantage in doing this: whilst Flavio can draw on his first-hand knowledge of the real case to introduce extenuating circumstances (as in lines 3-4, where he introduces the other client's reaction as grounds for having an argument), he does not have privileged access to this resource with regards the anecdotal case. It is therefore easier for Sandro to demonstrate his point (that one should not have an argument for trivial reasons) by shifting the focus away from the client's real case to an anecdotal case designed to unequivocally illustrate that point (i.e. the circumstances portrayed in the anecdote are ostensibly trivial and, therefore, do not justify having an argument).

A second type of evidence comes from TC staff members' use of third position repair (Schegloff, 1992). One of the ways in which clients can fail to extract and endorse the 
upshot of an anecdote is to treat it as a real case, which should be analysed in isolation rather then in its anecdotal relationship with the client's case. In response to this, TC staff engage in third position repair, specifying that the anecdote was an "example", a "case", and the like. This is shown in Extract 6 (see also Extract 4, lines 3-8).

(6) IntG7:74 23:41 'Violence'

S=staff, C=client

01 S-Gia: Prima hai detto che >vojo dir< hai aggredito before have-2S say-PSTP CMP want-1S say-INF have-2S attack-PSTP Before you said >I mean< that you attacked 
Pino - Delivering criticism through anecdotes in interaction

15

$(1.3)$

16 S-Gia: Ho >fatto un esempio.< Se offendo Paollo. K-1 have-1S make-PSTP an example if offend-1S NAME

I >made an example.< If I offend Paollo.

17

$(1.2)$

18 S-Gia: Uno a caso.

one at case

One at random.

19

(.)

20 S-Gia: Tognetti. SURNAME

Tognetti.

$(0.2)$

22 S-Gia:

Che è quello:: ( ) l'è fora da ogni REL be-3S the.one-M 3S.SCL=be-3S out from each Who i::s the one ( ) who is out of any

$\downarrow$ gioco. (>Vojo dire<) che è game want-1S say-INF CMP be-3S

$\downarrow$ game $^{2}$. (>I mean<) who is

24

il più tranquillo. the most calm

the quietest one.

$(0.5)$

26 S-Gia:

Se offendo eh- e::h Fabrizio.

if offend-1S PTC PTC NAME

If I offend uh- u::h Fabrizio.

$(0.4)$

28 S-Gia: Non pensi che sia violenz(h)a not think-2S CMP be-SBJ.3S violence

Don't you think that it is violenc(h)e

anche que:lla. Oppure lo mina:ccio.

also that-F or 3S.A threaten-1S

as well. Or ((if)) I threa:ten him.

30

$(2.5)$

31 C-Mar: Io non volevo offenderlo.

IS.N not want-IPF.1S offend-INF=3S.A

I didn't mean to offend him. 
Before Extract 6, the staff members attending the meeting invited Marco (a client) to reflect on his own conduct (apparently involving aggressive behaviours) over a recent period of time. Although Marco admitted making some negative verbal comments to others, he also minimised their seriousness by saying that they were not a form of violence (data not shown). At lines 1-3 Gianni (staff) refers back to that part of Marco's talk, then he introduces a hypothetical anecdote in which he (Gianni) offends a client (Roberto, copresent). At lines 7 and 9 Gianni solicits endorsement of the upshot of the anecdote (i.e. offending someone is a form of violence). However, Marco treats the case as real rather than hypothetical - i.e. as if Gianni was referring to the impact of Marco's conduct on another client in real life (lines 11-12). This treatment provides Marco with a basis for avoiding addressing the upshot conveyed through the anecdote ("Non lo so"/ "I don't know"). Gianni engages in third position repair, clarifying that the anecdote was "an example" ("un caso"; line 14). He then pursues endorsement of the conveyed principle through an iteration of the anecdote, now using a different client as a 'case' (line 16). He then self-repairs his selection of a client by selecting yet another client (line 20) and by marking this selection as motivated by picking a client "at random" ("a caso"; line 18) - i.e. ostensibly for illustrative purposes and not as a case to be examined independently (see 'Anecdotes Are Transpositions of Client Circumstances' section). These repair operations support my observation that TC staff members employ anecdotes to interdict client access to circumstantial detailing, which is possible when clients treat an event as real rather than anecdotal. Gianni repairs the treatment of the anecdote precisely after Marco has treated it as a real case and has proposed that knowing its details is necessary to issue an evaluation of it (lines 11-12). This staff-client misalignment about the treatment of the case as anecdotal vs. real reflects their divergent agendas. By treating the case as real, the client can subject it to empirical scrutiny - scrutiny which could lead to proving that the case is not as bad as the staff member is trying to make out, and therefore that it does not support the conveyed criticism (see Extract 1). By framing the case as anecdotal the staff member treats it as an empirically unverifiable and self-evident illustration of a principle, that is, the anecdote is taken to always convey the same principle regardless of what its empirical details may be (as evident in Gianni's orientation to the interchangeable and instrumental nature of referring to different clients for illustrative purposes, lines 16-26).

\section{Discussion}

Criticising someone's conduct is a disaffiliative action that can undermine social harmony and cohesion. This is an especially salient problem in settings where professionals encourage their clients to modify maladaptive or inappropriate behaviours (on the basis of some explicit or tacit set of standards), but they have to do so in ways that do not disrupt the relationship with their clients. Group meetings of the kind examined in this study add another layer of complexity to this task: when a client does not accept feedback in front of 
the group, this can compromise TC staff members' credibility and authority. The interactional use of anecdotes is a practice designed to circumvent these generic problems. The professionals whose practices I examined in this study (TC staff members) employ anecdotes indirectly to convey criticism of their clients' behaviours. Rather than criticising them directly, TC staff members introduce an anecdotal case which belongs to the same class of possible cases to which the target client's case also belongs. Because of the co-class connection between the real and the anecdotal case, the principle illustrated through the latter also applies to the former. By endorsing the principle conveyed through the anecdotal case, clients put themselves in a criticisable position; they accept the general validity of a norm of conduct which they have violated in the real case. Their conduct in the real case is therefore exposed as inappropriate or inadequate (Drew, 1992). The use of anecdotes enables TC staff members to achieve this outcome without commenting on their clients' conduct in any overt manner.

The study evidenced tensions over the epistemic treatment of cases as either anecdotal or real. Different ways of detailing an event can be used to support different assessments of it if one can claim legitimate access to those details. As long as clients can treat an event as real, they can invoke the details of its internal dynamic for an assessment of it (e.g. they can use circumstantial detailing to exonerate themselves from attributions of inadequate conduct, as Flavio does at the start of Extract 3). By treating a case as real clients can systematically avoid endorsing the principles whose illustration TC staff members ground on overtly simplified cases, stripped of all the nuances which almost unavoidably characterise real-life circumstances. Conversely, by treating a case as anecdotal TC staff members protect it from empirical testing and, therefore, design it as a self-evident and indisputable illustration of a norm.

\section{Role of funding}

The research leading to these results has received funding from the People Programme (Marie Curie Actions) of the European's Union Seventh Framework Programme (FP7/20072013) under REA grant agreement no 626893. The contents of this paper reflect only the views of the author and not the views of the European Commission.

\section{Acknowledgments}

I would like to thank: Mara Calta (Fondazione Exodus) and Gianluigi Formaggioni (Fondazione San Gaetano) for helping collect the data, and for all their support in several phases of the project; all the TC staff members and clients who appear in the recordings; Giovanni Rossi for sharing with me his glossing abbreviations, and for checking and amending the interlinear glosses in this paper; an anonymous reviewer for his thorough comments on an earlier version of this manuscript. Finally, my gratitude goes to Charles Antaki for his invaluable contribution to the analyses leading up to this paper, and for commenting on earlier versions of this manuscript. 


\section{Funding}

The research leading to these results has received funding from the People Programme (Marie Curie Actions) of the European's Union Seventh Framework Programme (FP7/20072013) under REA grant agreement no 626893. The contents of this paper reflect only the views of the author and not the views of the European Commission.

\section{Appendix: transcription conventions and abbreviations}

S-Gia Participant role ( $\mathrm{S}$ for staff, $\mathrm{C}$ for client) followed by the first three letters

C-Alb of their pseudonym

, ? Punctuation captures intonation, not grammar: Comma is for slightly upward 'continuing' intonation; question mark for marked upward intonation; and period for falling intonation.

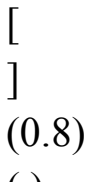

(.) wo:::rd

wo-

word

$\uparrow \downarrow$

$=$

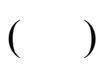

hhh .hhh

${ }^{\circ}$ word $^{\circ}$

((words))

"words"

$<-1$

$k-2$

Left-side brackets indicate where overlapping talk begins.

Right-side brackets indicate where overlapping talk ends.

Numbers in parentheses indicate silences in tenths of a second. A period inside parentheses is a silence less than two-tenths of a second.

Colons indicate a lengthening of the sound just preceding them, proportional to the number of colons.

A hyphen indicates an abrupt cut-off or self-interruption of the sound in progress indicated by the preceding letter(s).

Underlining indicates stress or emphasis (usually conveyed through slightly rising intonation).

An arrow symbol indicates a marked pitch rise or fall.

Equal signs at the end of one line and the start of an ensuing one indicate a "latched" relationship - no silence at all between them.

Empty parentheses indicate talk too obscure to transcribe. Words inside such parentheses indicate a best estimate of what is being said.

The letter ' $h$ ' is used to indicate hearable aspiration, its length proportional to the number of h's. If preceded by a dot, the aspiration is an in-breath. Aspiration internal to a word (e.g., laughter) is enclosed in parentheses.

Talk appearing within degree signs is lower in volume relative to surrounding talk.

Words in double parentheses indicate transcriptionist's comments.

Quotation marks indicate participants' use of direct reported speech.

Turn carrying the anecdote

Client response to the anecdote

\section{Abbreviations}


Pino - Delivering criticism through anecdotes in interaction

$1=$ first person

$2=$ second person

$3=$ third person

$\mathrm{A}=$ accusative

$\mathrm{AUG}=$ augmentative

$\mathrm{CL}=$ clitic

$\mathrm{CMP}=$ complementiser

$\mathrm{CND}=$ Conditional

$\mathrm{D}=$ dative

$\mathrm{EX}=$ existential

$\mathrm{F}=$ feminine

$\mathrm{G}=$ genitive

GER $=$ Gerund

FUT $=$ Future

$\mathrm{IM}=$ impersonal

IMP = Imperative

$$
\begin{aligned}
& \mathrm{INF}=\text { Infinitive } \\
& \text { IPF }=\text { Past Imperfect } \\
& \text { ITJ }=\text { interjection } \\
& \mathrm{M}=\text { masculine } \\
& \mathrm{N}=\text { nominative } \\
& \mathrm{NPST}=\text { Non-Past } \\
& \mathrm{PTC}=\text { particle } \\
& \mathrm{PST}=\text { Past } \\
& \mathrm{PSTP}=\text { Past Participle } \\
& \mathrm{PTV}=\text { partitive } \\
& \text { REL }=\text { relativiser } \\
& \mathrm{RFL}=\text { reflexive } \\
& \mathrm{S}=\text { singular } \\
& \mathrm{SBJ}=\text { Subjunctive } \\
& \mathrm{SCL}=\text { subject clitic }
\end{aligned}
$$

In absence of other tense/aspect/mood glosses, the unmarked verb inflection is Present Indicative (simple present).

\section{Notes}

${ }^{1}$ Although this is commonly translated as "invective", given the context it appears that Gianni means something like "sermon".

${ }^{2}$ Idiomatic; I take it to suggest that Tognetti (a client) is notoriously not involved in group dynamics (e.g. tensions, collusion, etc.) in which other clients are involved.

\section{References}

Arminen I and Halonen M (2007). Laughing with and at patients: The roles of laughter in confrontations in addiction group therapy The Qualitative Report 12(3): 484-513.

Drew $P$ (1992). Contested evidence in courtroom cross-examination: the case of a trial for rape. In: Drew P and heritage J (eds) Talk at work. Cambridge: Cambridge University Press.

Drew $\mathrm{P}$ (1998) Complaints about transgressions and misconduct. Research on Language and Social Interaction 31(3-4): 295-325.

Drew P (2003) Precision and Exaggeration in Interaction. American Sociological Review 68(6): 917-938.

Drew P and Holt E (1988) Complainable Matters: The Use of Idiomatic Expressions in Making Complaints. Social Problems 35(4): 398-417. 
Pino - Delivering criticism through anecdotes in interaction

Gill VT and Maynard DW (1995). On "Labelling" in Actual Interaction: Delivering and Receiving Diagnoses of Developmental Disabilities. Social Problems 42(1): 11-37. doi:10.1525/sp.1995.42.1.03x0453k

Heritage J (2011) Territories of knowledge, territories of experience: empathic moments in interaction. In: Stivers T, Mondada L, and Steensig J (eds) The Morality of Knowledge in Conversation. Cambridge: Cambridge University Press.

Jefferson G (1985) On the Interactional Unpackaging of a 'Gloss'. Language in Society 4: 435466.

Koshik I (2003) Wh-questions used as challenges. Discourse Studies 5(1): 51-77.

Lindström A and Sorjonen ML (2013) Affiliation in Conversation. In: Sidnell J and Stivers T (eds) The handbook of conversation analysis. Boston: Wiley-Blackwell, pp. 350-369.

MacMartin C and LeBaron CD (2006) Multiple involvements within group interaction: A video-based study of sex offender therapy. Research on Language and Social Interaction 39(1): 41-80. doi:10.1207/s15327973rlsi3901_3

Peräkylä A (1995) AIDS counselling: Institutional interaction and clinical practice. Cambridge: Cambridge University Press.

Pomerantz A and Heritage J (2013) Preference. In: Sidnell J and Stivers T (eds) The handbook of conversation analysis. Boston: Wiley-Blackwell, pp. 210-228.

Sandlund (2014) Prescribing conduct: Enactments of talk or thought in advice-giving sequences. Discourse Studies 16(5): 645-666.

Schegloff EA (1992). Repair after Next Turn: The Last Structurally Provided Defense of Intersubjectivity in Conversation. American Journal of Sociology 97(5): 1295-1345.

van Nijnatten C and van Elk E (2015). Communicating Care and Coercion in Juvenile Probation. British Journal of Social Work 45: 825-841.

Zemel (2014) Instructed experience: therapeutic enactment in emotionally focused therapy. In: Jacknick CM, Box C, and Waring $\mathrm{HZ}$ (eds) Talk in Institutions: A LANSI Volume. Cambridge Scholars Publishing, pp. 46-73. 